\title{
Utilization of herbal and nutritional compounds among older adults with bipolar disorder and with major depression
}

\author{
Daniel Keaton ${ }^{1}$, Nathan Lamkin ${ }^{1}$, Kristin A. Cassidy ${ }^{1}$, William J. Meyer ${ }^{1}$, Rosalinda V. Ignacio ${ }^{2}$, \\ Lakyntiew Aulakh ${ }^{3}$, Frederic C. Blow ${ }^{2}$ and Martha Sajatovic ${ }^{4 *}$ \\ ${ }^{1}$ Department of Psychiatry, Case Western Reserve University, Cleveland, OH, USA \\ ${ }^{2}$ Serious Mental Illness Treatment Research and Evaluation Center (SMITREC), Health Services Research and \\ Development, Ann Arbor VA Healthcare System and Department of Psychiatry, University of Michigan, Ann Arbor, MI, \\ USA \\ ${ }^{3}$ Hopital Regional de Sudbury, Regional Hospital, Sudbury, Ontario, Canada \\ ${ }^{4}$ Case Western Reserve University School of Medicine, University Hospitals Case Medical Center, Cleveland, OH, USA
}

\section{SUMMARY}

Objectives Herbal and nutritional compounds (HNC) are widely used among geriatric populations with depression, however little data exists on HNC use in older populations with bipolar disorder. The goal of this study was to evaluate orallyingested HNC use in individuals with bipolar disorder and with major depression.

Methods This was a cross-sectional analysis of self-reported factual knowledge of HNC, individual perspective on efficacy and safety of HNC, patterns of HNC use, and discussion of $\mathrm{HNC}$ with health care providers in 50 older adults with bipolar disorder and 50 older adults with major depression.

Results In this sample, approximately $30 \%$ of older individuals with depression or bipolar disorder used orally- ingested HNC. Over $40 \%$ of older adults believed that HNC is FDA-regulated and $14-20 \%$ preferred to take HNC compared to physician-prescribed psychotropic medications. Use of HNC was more common among older adults with bipolar disorder $(44 \%)$ compared to older adults with major depression $(16 \%, p=0.003)$. The majority of older adults with mood disorders $(64 \%)$ had not discussed use of HNC with their treating physicians.

Conclusion Orally ingested HNC was used by nearly one in three older adults with mood disorders, and was more common among those with bipolar disorder compared to those with major depression. Most individuals did not discuss HNC use with their physicians. Clinicians need to assess for HNC use, particularly with respect to potential drug-drug interactions. Copyright (C) 2009 John Wiley \& Sons, Ltd.

KEY WORDS - complementary medicine; alternative medicine; herbal compounds; nutritional supplements; mood disorders; geriatrics; depression; bipolar disorder

\section{INTRODUCTION}

Kennedy (2005) demonstrated that an estimated 38.2 million adults in the United States used complementary or alternative treatments in 2002, and use of herbal or nutritional compounds (HNC) in geriatric populations can be extensive (Cohen et al.,

\footnotetext{
*Correspondence to: Dr M. Sajatovic, Department of Psychiatry, University Hospitals Case Medical Center, 11100 Euclid Avenue, Cleveland, Ohio, 44106, USA.

E-mail: Martha.Sajatovic@uhhospitals.org
}

Copyright (C) 2009 John Wiley \& Sons, Ltd.
2002). Grzywaczs and colleagues (2006) demonstrated that $81.7 \%$ of older adults with depression or anxiety self-reported using complementary/alternative therapies in the past year, compared to $64.6 \%$ of elders without mental conditions. Kales and colleagues (2004) demonstrated that the prevalence of herbal and 'natural' product use among older adults may correlate with psychiatric symptoms and higher education levels; $75 \%$ of individuals were also taking potentially interacting medications. Older adults have also been identified as a group increasingly using $\mathrm{HNC}$ - however; these individuals may not discuss $\mathrm{HNC}$ use with their mainstream medical clinicians (Cohen et al., 2002). 
As with FDA-approved medications, there are potential benefits and adverse effects with $\mathrm{HNC}$, (Pittler and Ernst, 2000; Plushner, 2000; Ernst, 2002; Matthews et al., 2002; Izzo, 2004; Shibayama et al., 2004; Edie and Dewan, 2005; Linde et al., 2005; Fuller and Sajatovic, 2007; Meeks et al., 2007; Tachil et al., 2007; Andeescu et al., 2008). Orally ingested HNC may interact with conventional prescribed medications. For example, St John's Wort, has demonstrated efficacy in treating depression (Linde et al., 2005). However, serotonin syndrome has been reported with concomitantly prescribed antidepressant (Izzo et al., 2004; Shibayama et al., 2004). Ginkgo biloba may slow cognitive decline in dementia, however, bleeding complications, amplified by use of anticoagulant medication, are a concern (Ernst, 2002).

A better understanding of HNC use among older adults with mental disorders is needed in order to optimize care for this vulnerable population. This cross-sectional analysis of HNC use in older adults with bipolar and depressive disorders evaluated factual knowledge of $\mathrm{HNC}$, individual perspective of efficacy and safety of HNC, patterns of HNC use, and discussion of $\mathrm{HNC}$ with health care providers.

\section{METHODS}

This was a cross-sectional survey of 100 older adults with mood disorders (bipolar disorder $n=50$ and major depression $n=50$ ) on use of orally ingested HNC. The assessment period for which HNC use was evaluated was the last 3 months prior to the date of interview using a one-time, self-report survey. Demographic information was collected via participant self-report, and by medical record review. Selfreported use of $\mathrm{HNC}$ was evaluated on three primary domains including: (1) factual knowledge (HNC use in the US, FDA regulatory status, and potential medication interactions); (2) attitudes towards HNC (effectiveness in comparison to physician-prescribed medications, patient preference and perceived relative safety in comparison to physician-prescribed treatments); and (3) HNC practice (patterns of use and discussion with physician health providers). Questions asked about HNC were an exploratory effort to determine general attitudes and patterns of HNC use by older patients with bipolar and depressive disorders, and specific content was based upon the investigator's clinical experience in geriatric mooddisordered populations. The series of questions were intended to identify areas of potential clinical concern and inform future systematized analyses of HNC. HNC use was described to participants as 'Types of treatments that are also known as herbal medications, natural treatments or supplements, and individuals were provided with an example list of HNCs (Ernst, 2002; Fuller and Sajatovic, 2007) (Table 1). Oncedaily multivitamins were not included as HNC.

Individuals were also evaluated with respect to global psychopathology [Clinical Global Impression scale (CGI; Guy, 1976)], functional status [Global Assessment Scale (GAS; Endicott et al., 1976)], cognitive status [Mini Mental State Examination (MMSE; Folstein et al., 1975)], and self-reported adherence with prescribed psychotropic medications (percentage closest to $0 \%, 25 \%, 50 \%, 75 \%$ or $100 \%$ ) during the past 3 months. Standardized scales were administered by a trained rater.

All study participants met the following inclusion criteria: (1) Age 55 or older with DSM-IV-TR diagnosis of major depression or bipolar disorder; (2) without substantial cognitive impairment as evidenced by MMSE score of 22 or higher; (3) received treatment with prescribed psychotropic medications within the past 6 months; and (4) inpatients on a geropsychiatry unit, outpatients at a general outpatient clinic at an academic medical center, or outpatients at a Community Mental Health Clinic (CMHC). Inpatients were all stabilized patients in the discharge-planning phase who were asked to provide information on their $\mathrm{HNC}$ use prior to their hospitalization (average length of stay on the inpatient unit was approximately 1 week-10 days). Participants were referred by their clinicians/treatment team. The study was conducted at the academic medical center and the CMHC. All participants provided written, informed consent. This study was approved for use of human subjects by the local Institutional Review Board (IRB).

Table 1. Examples of commonly utilized herbal and nutritional compounds

\begin{tabular}{ll}
\hline Aloe & Ginseng \\
Bilberry & Glucosamine/Chondroitin \\
Black Cohosh & Golden Seal \\
Cartilage (bovine and shark) & Growth Hormone \\
Cayenne & Hawthorn \\
Chamomile & Kava Kava \\
Colloidal Silver Products & LaPacho \\
Dong Quai & Licorice \\
Echinacea & Melatonin \\
Ephedra & Milk Thistle \\
Feverfew & Peppermint \\
Garlic & St. John's Wort \\
Ginger & Saw Palmetto \\
Ginkgo & Valerian \\
& Zinc Supplements \\
\hline
\end{tabular}




\section{Data analysis}

Descriptive statistics were obtained on demographic and clinical characteristics, HNC knowledge, attitudes and practice, as well as scores on the CGI, GAS, and MMSE. Bipolar disorder and major depression groups were compared via $t$-test and chi-square analysis as appropriate. Statistical significance were adjusted for multiple comparisons using the Bonferroni method at $\alpha=0.10$ and adjusted level of significance of 0.004 .

\section{RESULTS}

\section{Clinical characteristics of older adults with serious mood disorders}

Table 2 identifies group demographic and clinical characteristics of all individuals, individuals with major depression $(n=50)$ and bipolar disorder $(n=50)$. Mean age was $68.7 \pm 9.74$ years. Over one-third of the sample were minorities (34\%), primarily AfricanAmerican. Clinical characteristics of bipolar vs depressed individuals were similar. Most individuals had mood disorder for 3-5 decades and were mildlymoderately ill as demonstrated by a global psychopathology (CGI) mean score of 3.2. Forty-seven percent $(n=47)$ were inpatients. Clinical characteristics of inpatients vs. outpatients were similar. Most of the patients were well-educated with a mean of $13.4 \pm 3.0$ years of education and were relatively cognitively intact with a mean MMSE of 28/30. Approximately one quarter of patients noted that they were at least partially non-adherent with prescribed psychotropic medications. While bipolar patients were numerically slightly less adherent to prescribed psychotropic than unipolar patients $(28 \%$ vs $14 \%)$ this was not statistically significant. Most individuals had between 2-3 medical conditions, with the most common being hypertension $(52 \%, n=52)$, diabetes/ endocrine abnormalities $(41 \%, n=41)$, dyslipidemia

Table 2. Demographic and clinical characteristics of older adults with major depression $(n=50)$ and bipolar disorder $(n=50)$

\begin{tabular}{|c|c|c|c|c|}
\hline Variable & $\begin{array}{l}\text { All patients } \\
(n=100)\end{array}$ & $\begin{array}{l}\text { Bipolar Disorder } \\
\quad(n=50)\end{array}$ & $\begin{array}{l}\text { Major Depression } \\
\quad(n=50)\end{array}$ & $\begin{array}{c}\text { Test } \\
\text { Statistics }\end{array}$ \\
\hline Age in years $($ mean $\pm \mathrm{SD})$ & $68.7 \pm 9.74$ & $66.2 \pm 8.90$ & $71.2 \pm 9.99$ & $\begin{array}{c}t=2.62 \\
\mathrm{df}=98, p=0.01 *\end{array}$ \\
\hline \multicolumn{5}{|l|}{ Ethnicity $(n, \%)$} \\
\hline African American & $29(29 \%)$ & $17(34 \%)$ & $12(24 \%)$ & \multirow{4}{*}{$\mathrm{ns}^{1}$} \\
\hline Caucasian & $66(66 \%)$ & $31(62 \%)$ & $35(70 \%)$ & \\
\hline Asian & $3(3 \%)$ & $1(2 \%)$ & $2(4 \%)$ & \\
\hline Other & $2(2 \%)$ & $1(2 \%)$ & $1(2 \%)$ & \\
\hline \multicolumn{5}{|l|}{ Gender $(n, \%)$} \\
\hline Women & $70(70.0 \%)$ & $32(64 \%)$ & $38(76 \%)$ & ns \\
\hline \multicolumn{5}{|l|}{ Marital Status $(n, \%)$} \\
\hline Married & $37(37 \%)$ & $13(26 \%)$ & $24(48 \%)$ & \multirow[t]{4}{*}{$\mathrm{ns}$} \\
\hline Single & $17(17 \%)$ & $10(20 \%)$ & $7(14 \%)$ & \\
\hline Widowed & $22(22 \%)$ & $11(22 \%)$ & $11(22 \%)$ & \\
\hline Divorced & $24(24 \%)$ & $16(32 \%)$ & $8(16 \%)$ & \\
\hline Education in years (mean $\pm S D)$ & $13.4 \pm 3.03$ & $13.4 \pm 3.11$ & $13.5 \pm 2.97$ & ns \\
\hline Age of Mood Disorder Onset in years $($ mean $\pm S D)$ & $41.2 \pm 22.13$ & $36.6 \pm 19.87$ & $45.9 \pm 23.52$ & ns \\
\hline Duration of Mood Disorder in years (mean $\pm S D$ ) & $26.8 \pm 21.86$ & $28.8 \pm 21.13$ & $24.6 \pm 22.63$ & ns \\
\hline Family history of psychiatric illness $(n, \%)$ & $50(53 \%)$ & $28(61 \%)$ & $22(46 \%)$ & ns \\
\hline Lifetime substance abuse $(n, \%)$ & $15(15 \%)$ & $7(15 \%)$ & $8(16 \%)$ & ns \\
\hline Number of prescribed psychiatric medications (mean \pm SD) & $2.74 \pm 1.52$ & $2.61 \pm 1.59$ & $2.88 \pm 1.44$ & ns \\
\hline Number of co-morbid medical illnesses (mean $\pm \mathrm{SD}$ ) & $2.89 \pm 2.00$ & $2.75 \pm 2.14$ & $3.02 \pm 1.87$ & ns \\
\hline $\begin{array}{l}\text { Number of prescribed medications for comorbid medical } \\
\text { problems (mean } \pm \text { SD) }\end{array}$ & $5.80 \pm 4.40$ & $5.39 \pm 4.82$ & $6.20 \pm 3.94$ & ns \\
\hline Global Assessment Scale (GAS) $($ mean \pm SD) & $57.9 \pm 16.54$ & $59.7 \pm 17.62$ & $56.0 \pm 15.33$ & ns \\
\hline Mini Mental State Examination (mean \pm SD) & $27.6 \pm 2.24$ & $27.7 \pm 1.98$ & $27.5 \pm 2.49$ & ns \\
\hline Clinical Global Impression (CGI) (mean \pm SD) & $3.2 \pm 1.15$ & $3.1 \pm 1.20$ & $3.3 \pm 1.10$ & ns \\
\hline Partial/poor adherence with prescribed psychotropic medications ${ }^{2}$ & $\begin{array}{c}n=97 \\
20(21 \%)\end{array}$ & $\begin{array}{c}n=47 \\
13(28 \%)\end{array}$ & $\begin{array}{c}n=50 \\
7(14 \%)\end{array}$ & ns \\
\hline
\end{tabular}

${ }^{1}$ Comparing ethnicity Caucasian vs Others.

${ }^{2}$ Based upon self-reported adherence with prescribed psychotropic medications in the previous 3 months. Partial or poor adherence defined as taking $75 \%$ or less of prescribed psychotropic medication.

$\mathrm{ns}=$ not significant.

*Not statistically significant after adjusting for multiple comparisons. 
(32\%, $n=32)$, arthritis / rheumatic conditions (26\%, $n=26)$, gastrointestinal conditions $(25 \%, n=25)$, and cardiovascular/coronary artery disease $(20 \%, n=20)$.

\section{HNC factual knowledge, attitudes and practice}

Table 3 demonstrates HNC knowledge, attitudes and practice among older adults with mood disorders.
Individuals were defined as knowledgable if they knew how common complementary/alternative medicine use in the U.S. is, and were aware of FDAregulatory status, and potential for $\mathrm{HNC}$ to interact with prescribed medications. Approximately $36-50 \%$ incorrectly believed that the FDA regulates $\mathrm{HNC}$ to ensure safety for the American Public. However, most individuals (56-66\%) correctly believed that $\mathrm{HNC}$

Table 3. Knowledge, attitudes and practice of orally ingested herbal and nutritional compounds (HNC) among 100 older adults with mood disorders

\begin{tabular}{|c|c|c|c|c|}
\hline Statement & $\begin{array}{l}\text { All Patients } \\
(n=100)\end{array}$ & $\begin{array}{l}\text { Major Depression } \\
\quad(n=50)\end{array}$ & $\begin{array}{l}\text { Bipolar Disorder } \\
\quad(n=50)\end{array}$ & $\begin{array}{c}\text { Test } \\
\text { Statistic }\end{array}$ \\
\hline \multicolumn{5}{|c|}{ 1. Complementary/alternative medicine is used by at least one-third of the American Public } \\
\hline Agree & $43(43 \%)$ & $17(34 \%)$ & $26(52 \%)$ & \multirow[t]{3}{*}{ ns } \\
\hline Neutral/Don’t Know & $52(52 \%)$ & $28(56 \%)$ & $24(48 \%)$ & \\
\hline Disagree & $5(5 \%)$ & $5(10 \%)$ & $0(0 \%)$ & \\
\hline \multicolumn{5}{|c|}{ 2. The FDA regulates HNC to ensure their safety for the American Public } \\
\hline Agree & $43(43 \%)$ & $25(50 \%)$ & $18(36 \%)$ & \multirow{3}{*}{ ns } \\
\hline Neutral/Don’t Know & $31(31 \%)$ & $17(34 \%)$ & $14(28 \%)$ & \\
\hline Disagree & $26(26 \%)$ & $8(16 \%)$ & $18(36 \%)$ & \\
\hline \multicolumn{5}{|c|}{ 3. HNC may in some cases interact with medications prescribed by a person's doctor } \\
\hline Agree & $61(61 \%)$ & $28(56 \%)$ & $33(66 \%)$ & \multirow[t]{3}{*}{ ns } \\
\hline Neutral/Don’t Know & $28(28 \%)$ & $16(32 \%)$ & $12(24 \%)$ & \\
\hline Disagree & $11(11 \%)$ & $6(12 \%)$ & $5(10 \%)$ & \\
\hline \multicolumn{5}{|c|}{ 4. HNC is generally not as effective compared to medications prescribed by a person's doctor } \\
\hline Agree & $33(33 \%)$ & $20(40 \%)$ & $13(26 \%)$ & \multirow[t]{3}{*}{ ns } \\
\hline Neutral/Don’t Know & $47(47 \%)$ & $21(42 \%)$ & $26(52 \%)$ & \\
\hline Disagree & $20(20 \%)$ & $9(18 \%)$ & $11(22 \%)$ & \\
\hline \multicolumn{5}{|c|}{ 5. HNC is equal /more effective compared to medications prescribed by a person's doctor } \\
\hline Agree & $20(20 \%)$ & $9(18 \%)$ & $11(22 \%)$ & \multirow[t]{3}{*}{ ns } \\
\hline Neutral/Don’t Know & $44(44 \%)$ & $21(42 \%)$ & $23(46 \%)$ & \\
\hline Disagree & $36(36 \%)$ & $20(40 \%)$ & $16(32 \%)$ & \\
\hline \multicolumn{5}{|c|}{ 6. I prefer to take HNC compared to medications prescribed by my doctor. } \\
\hline Agree & $17(17 \%)$ & $7(14 \%)$ & $10(20 \%)$ & \multirow[t]{3}{*}{ ns } \\
\hline Neutral/Don’t Know & $20(20 \%)$ & $7(14 \%)$ & $13(27 \%)$ & \\
\hline Disagree & $62(63 \%)$ & $36(72 \%)$ & $26(53 \%)$ & \\
\hline \multicolumn{5}{|c|}{ 7. $\mathrm{HNC}$ is safer than medications prescribed by a doctor. } \\
\hline Agree & $14(14 \%)$ & $8(16 \%)$ & $6(12.2 \%)$ & \multirow[t]{3}{*}{ ns } \\
\hline Neutral/Don’t Know & $43(43 \%)$ & $18(36 \%)$ & $25(51.0 \%)$ & \\
\hline Disagree & $42(42 \%)$ & $24(48 \%)$ & $18(36.7 \%)$ & \\
\hline \multicolumn{5}{|l|}{ 8. I use $\mathrm{HNC}$} \\
\hline Yes & $30(30 \%)$ & $8(16 \%)$ & $22(44 \%)$ & \multirow[t]{2}{*}{$\chi^{2}=8.973, \mathrm{df}=1, p=0.003$} \\
\hline No & $69(70 \%)$ & $41(84 \%)$ & $28(56 \%)$ & \\
\hline \multicolumn{5}{|l|}{ 9. I use HNC daily } \\
\hline Yes & $18(18 \%)$ & $3(6 \%)$ & $15(30 \%)$ & \multirow[t]{2}{*}{$\chi^{2}=9.485, \mathrm{df}=1, p=0.002$} \\
\hline No & $81(82 \%)$ & $46(94 \%)$ & $35(60 \%)$ & \\
\hline \multicolumn{5}{|c|}{ 10. I use $\mathrm{HNC}$ at least once a week } \\
\hline Yes & $26(26 \%)$ & $6(12 \%)$ & $20(40 \%)$ & \multirow[t]{2}{*}{$\chi^{2}=9.844, \mathrm{df}=1, p=0.002$} \\
\hline No & $73(74 \%)$ & $43(88 \%)$ & $30(60 \%)$ & \\
\hline \multicolumn{5}{|c|}{ 11. I use $\mathrm{HNC}$ in addition to medications prescribed by my doctor } \\
\hline Yes & $29(29 \%)$ & $8(16 \%)$ & $21(42 \%)$ & \multirow[t]{2}{*}{ ns } \\
\hline No & $70(71 \%)$ & $41(84 \%)$ & $29(58 \%)$ & \\
\hline \multicolumn{5}{|c|}{ 12. I have used $\mathrm{HNC}$ in the past } \\
\hline Yes & $48(57 \%)$ & $15(39 \%)$ & $33(73 \%)$ & $\chi^{2}=10.374, \mathrm{df}=1, p=0.001$ \\
\hline No & $36(43 \%)$ & $24(62 \%)$ & $12(27 \%)$ & \\
\hline 13. I have discussed use & $\mathrm{C}$ with my do & & & \\
\hline Yes & $25(36 \%)$ & $5(16 \%)$ & $20(53 \%)$ & $\chi^{2}=9.846, \mathrm{df}=1, p=0.002$ \\
\hline No & $44(64 \%)$ & $26(84 \%)$ & $18(47 \%)$ & \\
\hline
\end{tabular}

** Discussion of HNC with doctor independent of whether individual was using CAM or not using HNC. 
could in some cases interact with prescribed medications.

With respect to perceived efficacy and safety of HNC, most individuals were either neutral or disagreed with the notion that HNC was equal to or more effective than prescribed medication treatments, while 14-20\% preferred HNC over prescribed medications, and $12-16 \%$ felt that HNC is safer than prescribed medications.

Approximately $30 \%$ of older adults with bipolar and depressive disorders reported using HNC. Of the total sample, $18 \%$ of patients reported using HNC daily, while $26 \%$ reported HNC use at least once per week. Older adults with bipolar disorder reported significantly more use of HNC than older adults diagnosed with depression $(n=22,44 \%$ of the bipolar group vs $n=8,16 \%$ of the depression group, $(p=0.003)$. There was no significant difference between those that self-reported using HNC vs. those with no HNC use with respect to adherence with prescribed psychotropic medications. There was also no significant difference in reported CAM use between inpatients and outpatients. Finally, over half $(n=20,53 \%)$ of individuals with bipolar disorder reported discussing HNC use with physicians compared to only $16 \%$ $(n=5)$ of individuals with depression $(p=0.002)$.

\section{DISCUSSION}

These findings support research showing HNC use to be common among psychiatric populations, and older adults (Unutzer et al., 2000; Cohen et al., 2002; Alderman and kiepfer, 2003; Grzywacz, 2006). In the group presented here, approximately one-third of older adults with bipolar and depressive disorders used orally ingested HNC, somewhat lower than the $54 \%$ of individuals with depression using alternative treatments in a 2001 US survey (Kessler et al., 2001). It has been reported that depression is one of the ten most frequent indications for using HNC (Astin, 1998; Kessler et al., 2001).

To the best of our knowledge, there are no previous reports on $\mathrm{HNC}$ use specifically in older adults with bipolar disorder. In our sample, HNC use was more common among bipolar elders $v s$ elders with major depression. A study of broadly defined alternative health care practices (Russinova et al., 2002) including 70 mixed age (mean 46.6 years) individuals with bipolar disorder and 39 individuals with depression noted herb use in $20 \%$ of bipolar and $10 \%$ of depressed individuals, and nutritional supplement use in $14 \%$ of bipolar and $10 \%$ of depressed individuals. However, in this report (Russinova et al., 2002) there were no statistically significant differences between populations with different diagnoses in either herb or nutritional supplement use, possibly related to small sample size.

Older adults with mood disorders in the study presented here were only moderately informed regarding $\mathrm{HNC}$ use and in understanding lack of FDAregulation of HNC. There were minimal differences between diagnostic groups on HNC factual knowledge. With respect to attitudes towards $\mathrm{HNC}$, a substantial minority (18-22\%) of individuals felt that HNC was as effective or was more effective compared to medications prescribed by physicians, and $12-16 \%$ of individuals preferred HNC over prescribed medications. It is possible that older individuals with mood disorders may have relatively high comfort with CAM because of (incorrect) perception that CAM compounds are closely monitored for safety by the federal government. Alternately, comfort with HNC may arise from misperception that products that are 'natural' or 'non-chemical' may be somehow safer than prescription medications.

Russinova et al. (2002) surveyed perceived benefits of complementary/alternative treatments among 157 individuals with serious mental illness (SMI). In this report (Russinova et al., 2002) individuals with SMI attributed improved physical, emotional and cognitive functioning with alternative health practices, and the investigators suggested that alternative practices, 'seem to promote a recovery process beyond the management of emotional and cognitive impairments, by also enhancing social, spiritual, general and selffunctioning'. The report by Russinova et al. included spiritual practices in addition to meditation, massage, guided imagery, yoga and chiropractic interventions, in contrast to the study presented here which focused on orally ingested HNC.

In our sample, just over $36 \%$ of older adults with mood disorders reported having discussed HNC with their doctor. Similarly, Kennedy (2005), found that only $33 \%$ of the general patient population told their primary care provider about their complementary/alternative treatment use. It is possible that patients were reluctant to report the use of HNC not prescribed by their doctor, or were simply unaware that this piece of information could be medically important. In the results reported here, individuals with bipolar disorder more frequently noted discussing $\mathrm{HNC}$ use (53\%) with their physicians compared to those with depression (16\%). It is possible that depressed patients being treated by primary care 
providers may have less time to talk about alternative practices, compared to bipolar patients who may be more likely to see psychiatrists who may have longer patient visits (and presumably would discuss alternative health practices).

The number of medications an individual is typically prescribed has been demonstrated to be increased with age (Kaufman et al., 2002; Cannon et al., 2006; Hayes, 2007) and among those with mental disorders (Ananth, 2004; Kreyenbuhl, 2007; Morrato, 2007). Older adults in this sample had, on average, between 2-3 medical conditions in addition to their mood disorders, with concomitant use of, on average, 5-6 medications for medical comorbidity and 2-3 medications for psychiatric illness. There was no difference in non-adherence rates for prescribed psychotropic medications between patients that took $\mathrm{HNC}$ vs. those not taking HNC, although it is possible that non-adherence rates were underestimated in this study because of the self-report methodology. As the evidence mounts in the direction of doctors being mostly unaware of the prevalent use of HNC by their patients who could be on potentially interacting medications, health care providers need to be particularly diligent in their assessment of HNC use among individuals with mood symptoms.

The results of this study should be interpreted in the light of multiple limitations including relatively small sample size, clinically-based, chart-review diagnostic criteria, relative gender and ethnic homogeneity and the fact that this was a 'young-old' (mean age 68.7) geriatric population. Latino and Asian populations were not well-represented in this clinical population from Northeastern Ohio, and findings might potentially have been different had there been more ethnic/ cultural diversity or if the study population had generally lower levels of education. Additional factors to consider when interpreting the results of this study are the inherent limitations of using self-report measures and the fact that the study did not evaluate use of spiritual practices or mind/body work known to be important to individuals with mental disorders (Jorm et al., 2002; Russinova et al., 2002; Grzywacz, 2006). Finally, the study did not evaluate the specific types of HNC utilized by patients in the study, why they chose to use HNC, or whether individuals used HNC in place of, or in addition to, psychotropic medications prescribed by their physicians. The HCN example list was not an all-inclusive list of all complementary or alternative treatments and some individuals may not have identified HCN that they were actually taking as it was not noted on the sample list.

\section{KEY POINTS}

- Herbal and nutritional compounds (HNC) are widely used among geriatric populations with depression, however little data exists on HNC use in older populations with bipolar disorder.

- In this study, orally ingested HNC were used by nearly one in three older adults with mood disorders, and was more common among those with bipolar disorder compared to those with major depression. Most individuals did not discuss HNC use with their physicians.

- Clinicians need to assess for HNC use, particularly with respect to potential drug-drug interactions.

\section{CONCLUSIONS}

In the sample assessed here, HNC was used by nearly one in three older adults with mood disorders, and was more common among bipolar elders compared to elders with major depression. Most individuals did not discuss HNC use with their physicians. Clinicians need to actively seek information about possible use of HNC, particularly with respect to potential drug-drug interactions. A comprehensive sample list of HNC may help patients and care providers to identify HNC that may be used in clinical settings. Finally, additional studies are needed to more fully explore HNC use in older adult populations with mood disorders.

\section{CONFLICT OF INTEREST}

Dr Sajatovic has received grants from GlaxoSmithKline, is a consultant to AstraZeneca and is on the Speakers Bureau for AstraZeneca.

\section{ACKNOWLEDGEMENTS}

The authors wish to extend special thanks to Nora Finnegan, BSN for assistance with data collection.

Previous presentations: Portions of this data were presented at the Cambridge/Luton International Conference on Mental Health 2007 in Cambridge, England, October 11-13, 2007 and the American Association of Geriatric Psychiatry (AAGP), March 15, 2008

\section{REFERENCES}

Alderman CP, Kiepfer B. 2003. Complementary medicine use by psychiatry patients of an Australian hospital. Ann Pharmacother 37(12): 1779-1780. 
Ananth J. 2004. Antipsychotic polypharmacy. Curr Pharm 10(18): $2231-2238$

Andreescu C, Mulsant BH, Emanuel JE. 2008. Complementary and alternative medicine in the treatment of bipolar disorder-a review of the evidence. J Affect Disord, 110(1-2): 16-26.

Cannon KT, Choi MM, Zuniga MA. 2006. Potentially inappropriate medication use in elderly patients receiving home health care: a retrospective data analysis. Am J Geriatr Pharmacother 4(2): 134-143.

Cohen RJ, Ek K, Pan CS. 2002. Complementary and alternative medicine (CAM) use by older adults: a comparison of self-report and physician chart documentation. J Gerontol A Biol Sci Med Sci 57(4): M223-M227.

Edie CF, Dewan N. 2005. Which psychotropics interact with four common supplements. Curr Psychiatry 4(1): 17-30.

Endicott J, Spitzer RL, Fleiss JL, Cohen J. 1976. The global assessment scale. A procedure for measuring overall severity of psychiatric disturbance. Arch Gen Psychiatry 33(6): 766-7771.

Ernst E. 2002. The risk-benefit profile of commonly used herbal therapies: Gingko, St. John's wort, Ginseng, Echinacea, Saw palmetto, and Kava. Annals Intern Med 136: 42-53.

Folstein MF, Folstein SF, McHugh PR. 1975. 'Mini Mental State'. A practical method for grading the cognitive state of patients for the clinician. J Psychiatr Res 12(3): 189-198.

Fuller M, Sajatovic M (eds). 2007. Drug Information Handbook for Psychiatry, 6th ed. Lexi-Comp., Inc.: Cleveland, $\mathrm{OH}$.

Grzywacz JG, Suerken CK, Quandt SA, et al. 2006. Older adults use of complementary and alternative medicine for mental health: findings from the 2002 National Health Interview Survey. J Altern Complement Med 12(5): 467-473.

Guy W. 1976. Clinical Global Impressions. ECDEU Assessment Manual for psychopharmacology. Publication No. (ADM). US Department of Health, Education, and Welfare (DHEW): Rockville, MD; 76-338.

Hayes BD. 2007. Polypharmacy and the geriatric patient. Clin Geriatr Med 23(2): 371-390.

Izzo AA. 2004. Drug interactions with St. John's wort (Hypericum perforatum): a review of the clinical evidence. Int J Clin Pharacol Ther 42(3): 139-148.

Jorm AF, Christensen H, Griffiths KM, Rodgers B. 2002. Effectiveness of complementary and self-help treatments for depression. Med J Aust 176 (Suppl): S84-S96.

Kales HC, Blow FC, Welsh DE, Mellow AM. 2004. Herbal products and other supplements: use by elderly veterans with depression and dementia and their caregivers. $J$ Geriatr Psychiatry Neurol 17(1): 25-31.

Kaufman DW, Kelly JP, Rosenberg L, et al. 2002. Recent patterns of medication use in the ambulatory adult population of the United States. JAMA 287: 337-344.

Kennedy J. 2005. Herb and supplement use in the US adult population. Clin Ther 27(11): 1847-1858.

Kessler RC, Soukup J, Davis RB, et al. 2001. The use of complementary and alternative therapies to treat anxiety and depression in the United States. Am J Psychiatry 158(2): 289-294.

Kreyenbuhl JA. 2007. Long-term antipsychotic polypharmacy in the VA health system: patient characteristics and treatment patterns. Psychiatr Serv 58(4): 489-495.

Linde K, Berner M, Egger M, Mulrow C. 2005. St. John's wort for depression: meta-analysis of randomized controlled trials. $\mathrm{Br} \mathrm{J}$ Psychiatry 186: 99-107.

Matthews JM, Etheridge AS, Black SR. 2002. Inhibition of human cytochrome P450 activities by kava extract and kava lactones. Drug Metab Dispos 30: 1153-1157.

Meeks TW, Wetherell JL, Irwin MR, et al. 2007. Complementary and alternative treatments for late-life depression, anxiety and sleep disturbance: a review of randomized controlled trials. J Clinical Psychiatry 68(10): 1461-1471.

Morrato EH. 2007. Prevalence, utilization patterns, and predictors of antipsychotic polypharmacy: experience in a multistate Medicaid population, 1998-2003. Clin Ther 29(1): 183-195.

Pittler MH, Ernst E. 2000. Efficacy of kava extract for treating anxiety; systematic review and meta-analysis. J Clin Psychopharacol 20: 84-89.

Plushner SL. 2000. Valeriana officinalis. Am J Health-Syst Pharm 57: $328-335$.

Russinova Z, Wewiorski NJ, Cash D. 2002. Use of alternative health care practices by persons with serious mental illness: Perceived benefits. Am J Public Health 92(10): 1600-1603.

Shibayama Y, Ikeda R, Motoya T, Yamada K. 2004. St. John's wort (Hypericum performatum) induces over expression of multidrug resistance protein 2(MRP2) in rats: a 30-day ingestion study. Food Chem Toxicol 42(6): 995-1002.

Tachil AF, Mohan R, Bhugra D. 2007. The evidence base of complementary and alternative therapies in depression. $J$ Affect Disord 97(1-3): 23-35.

Unutzer J, Klap R, Sturm R, et al. 2000. Mental disorder and the use of alternative medicine: results from a national survey. Am J Psychiatry 157(11): 1851-1857. 